\title{
Alterations in the glycome after HDAC inhibition impact oncogenic potential in epigenetically plastic SW13 cells
}

\author{
McKale R. Montgomery ${ }^{1}$ and Elizabeth E. Hull ${ }^{*}$
}

\begin{abstract}
Background: Defects in the type and degree of cellular glycosylation impact oncogenesis on multiple levels. Although the type of glycosylation is determined by protein sequence encoded by the genome, the extent and modifications of glycosylation depends on the activity of biosynthetic enzymes and recent data suggests that the glycome is also subject to epigenetic regulation. This study focuses on the ability of HDAC inhibition to alter glycosylation and to lead to pro-oncogenic alterations in the glycome as assessed by metastatic potential and chemoresistance.

Methods: Epigenetically plastic SW13 adrenocortical carcinoma cells were treated with FK228, an HDAC inhibitor with high affinity for HDAC1 and, to a lesser extent, HDAC2. In comparing HDAC inhibitor treated and control cells, differential expression of glycome-related genes were assessed by microarray. Differential glycosylation was then assessed by lectin binding arrays and the ability of cellular proteins to bind to glycans was assessed by glycan binding arrays. Differential sensitivity to paclitaxel, proliferation, and MMP activity were also assessed.

Results: Treatment with FK228 alters expression of enzymes in the biosynthetic pathways for a large number of glycome related genes including enzymes in all major glycosylation pathways and several glycan binding proteins. $84 \%$ of these differentially expressed glycome-related genes are linked to cancer, some as prognostic markers and others contributing basic oncogenic functions such as metastasis or chemoresistance. Glycan binding proteins also appear to be differentially expressed as protein extracts from treated and untreated cells show differential binding to glycan arrays. The impact of differential mRNA expression of glycosylation enzymes was documented by differential lectin binding. However, the assessment of changes in the glycome is complicated by the fact that detection of differential glycosylation through lectin binding is dependent on the methods used to prepare samples as protein-rich lysates show different binding than fixed cells in several cases. Paralleling the alterations in the glycome, treatment of SW13 cells with FK228 increases metastatic potential and reduces sensitivity to paclitaxel.
\end{abstract}

Conclusions: The glycome is substantially altered by HDAC inhibition and these changes may have far-reaching impacts on oncogenesis.

Keywords: Glycome expression, HDAC inhibition, Chemoresistance, Gene expression profiling, Glycan Array, Lectin Array, Epigenetics

\footnotetext{
* Correspondence: ehull@midwestern.edu

${ }^{2}$ Biomedical Sciences Program, College of Graduate Studies, Midwestern

University, Glendale, AZ 85308, USA

Full list of author information is available at the end of the article
}

(c) The Author(s). 2019 Open Access This article is distributed under the terms of the Creative Commons Attribution 4.0 International License (http://creativecommons.org/licenses/by/4.0/), which permits unrestricted use, distribution, and reproduction in any medium, provided you give appropriate credit to the original author(s) and the source, provide a link to the Creative Commons license, and indicate if changes were made. The Creative Commons Public Domain Dedication waiver (http://creativecommons.org/publicdomain/zero/1.0/) applies to the data made available in this article, unless otherwise stated. 


\section{Background}

Proper glycosylation of the dense layer of glycoconjugates on the cell surface is necessary for effective communication between cells and the environment. Aberrant glycosylation in cancer is associated with disrupted cell signaling, evasion of growth suppressors, immunoresistance, increased angiogenesis, and induction of invasion and metastasis [1-3]. Furthermore, both defective and increased levels of glycosylation have been shown to contribute to multidrug resistance in various cancers $[4,5]$. As such, a better understanding of the cancer glycome and glycoproteome will be instrumental to the identification of more definitive cancer biomarkers and development of more effective cancer therapeutics.

Ultimately, the versatility of glycan structures help cancer cells respond, adapt, migrate, and invade. Although there is no genetic template for glycan structure, the type of glycosylation added to any particular protein is unequivocally determined by consensus sequences in the gene encoding for it. The structure of the glycan added then depends on expression of the enzymes required to synthesize the carbohydrate glycan structures. Thus, glycome regulation is complex, and involves more than 600 so-called "glycogenes" which encode for the various proteoglycans, glycosyltransferases, glycosidases, sulfatases, and carbohydrate biosynthetic enzymes that determine glycome function. Evidence suggests that individual glycome composition is largely genetically predetermined, but recent advances in glycobiology have identified disease- and cancer-specific glycophenotypes which are under epigenetic control [6-8]. This is intriguing because unlike genetic mutations, epigenetic modifications are transient and reversible, making them extremely desirable therapeutic targets.

HDAC inhibitors are powerful epigenetic regulators and promising cancer therapeutics, but in solid tumors, these drugs are not effective as single agents, and instead are often use in combination with a chemotherapeutic. Furthermore, the broad-spectrum and often pleiotropic effects off HDAC inhibitors make it difficult to harness their full potential. Indeed, while growth rate is slowed by HDAC inhibitor treatment in nearly all cancer cells, many also increase oncogenic properties such as increased motility and invasive capacity [9]. Although other epigenetic regulators, such as the DNA methyltransferase inhibitor 5-Aza-dc, have been used extensively in multiple cancer types to effectively target glycogenes and glycosylation enzymes to slow tumor progression [10-12], the effects of HDAC inhibitors on glycosylation, oncogenic phenotype, and chemotherapeutic response have not been extensively investigated. At a broader level, even though epigenetic regulation determines many aspects of oncogenesis and normal cellular behavior, these epigenetic processes and their regulation are not well understood.

In the study of epigenetic regulation of the glycome, the human adrenal cortical carcinoma SW13 cell line represents an invaluable research model as it exists as two distinct phenotypes which are epigenetically plastic $[13,14]$. In this study, we utilize the SW13 cell line as a model of epigenetic phenotype regulation to investigate how HDAC inhibitors can influence the acquisition of distinct oncogenic characteristics, such as rapid proliferation and metastatic capacity. Data presented here suggest that HDAC inhibition significantly impacts the SW13 glycome. Specifically, we demonstrate differential glycogene expression in multiple biosynthetic pathways and document changes in glycome composition. We then go on to characterize the glycosylation signatures and glycan binding preferences of tumorigenic versus metastatic SW13 cells. Finally, we demonstrate that the changes induced by HDAC inhibitor treatment observed in the SW13 glycome are associated with decreased chemosensitivity. This work furthers our understanding of how HDAC inhibition might influence malignant transformation in cancer cell types that respond negatively to HDAC inhibitor treatment. This study also identifies candidate biomarkers for determining responsiveness to HDAC inhibition and chemotherapeutic treatments.

\section{Methods}

\section{SW13 cell culture and treatment}

SW13 cells were obtained from American Type Culture Collection (ATCC; CCL-105) and maintained in high glucose DMEM supplemented with $10 \%$ fetal bovine serum and $10 \mathrm{U} / \mathrm{ml}$ penicillin/streptomycin at $37^{\circ} \mathrm{C}$ in a humidity controlled incubator. For HDAC inhibition, cells were treated with $1 \mathrm{nM}$ romidepsin (FK228) (Selleckchem) for $24 \mathrm{~h}$.

\section{Morphology, proliferation, and MMP activity assays}

Morphology was assessed via immunofluorescence using standard techniques. Specifically, SW13 control cells, or SW13 cells that had been treated with $1 \mathrm{nM}$ FK228 were fixed with $4 \%$ paraformaldehyde, permeabilized with $0.2 \%$ Triton-X, and blocked with $1 \%$ BSA before a $1 \mathrm{~h}$ incubation with $25 \mathrm{U} / \mathrm{ml}$ Alexafluor 488 phalloidin (Invitrogen). Samples were mounted with ProLong Gold anti-fade reagent with DAPI to stain nuclei and photographed using a Zeiss Axiovert apotome with a 40X objective lens and a uniform exposure at each wavelength.

SW13 cell proliferation with and without 1 nM FK228 treatment was measured using a Click-iT EdU assay (ThermoFisher) according to the manufacturer's instructions. Cells were imaged using a Zeiss Axiovert Apotome 
with a 10X objective lens and uniform exposure at each wavelength. Percent proliferation was quantified using NIH ImageJ software to divide the number of cells which stained positive for EdU by the total number of cells in each groups.

MMP activity was measured by plating SW13 cells at $1 \times 10^{4}$ cells/well in 8 -chamber slides. After $24 \mathrm{~h}$ of no treatment (control) or treatment with $1 \mathrm{nM}$ FK228 cells were incubated overnight with a DQ gel substrate (Life Technologies) diluted to $40 \mu \mathrm{g} / \mathrm{ml}$ in MMP activity buffer $(100 \mathrm{mM} \mathrm{NaCl}, 100 \mathrm{mM}$ Tris-HCl, pH 7.5, $10 \mathrm{mM} \quad \mathrm{CaCl}_{2}, 20 \mu \mathrm{M} \mathrm{ZnCl}, 0.05 \% \quad \mathrm{NP} 40,0.2 \mathrm{mM}$ sodium azide). Cells were then washed 2 times with $1 \mathrm{X}$ PBS before fixation and DAPI staining. Relative differences in MMP activity were quantified using $\mathrm{NIH}$ Image J software to divide the relative amount of green fluorescence by the number of cells in a given well. All experiments were performed at least in triplicate.

\section{Gene expression analysis of SW13 cells following HDAC inhibitor treatment}

Total RNA was isolated from cells using Trizol according to the manufacturer's recommendations. Following quality control analysis $(260 / 230>1.5,260 / 280>1.8$, RIN > 6), whole genome microarray analysis was performed by PhalanxBiotech using their OneArray platform. Standard selection criteria to identify differentially expressed genes were established as $\log 2$ fold change $\geq 1$ and $p<0.05$. For advanced data and pathway analysis, intensity data were pooled and calculated to identify differentially expressed genes based on the threshold of fold change and $p$-value. A gene set enrichment analysis of Gene Ontology (GO) terms was then performed using the differentially expressed gene lists as input. A small subset of differentially expressed genes identified in the array were selected for validation by qRT-PCR. Briefly, the same total RNA described above was reverse transcribed using SuperScript II, and qRT-PCR was performed using $50 \mathrm{ng}$ cDNA per reaction on an $\mathrm{ABI}$ StepOne Plus thermocycler using SYBR Green chemistry. Expression changes were analyzed via the ${ }^{{ }^{\Delta}} C_{\mathrm{T}}$ Method following normalization to GAPDH expression, which was utilized as an invariant control.

\section{Lectin and glycan array analysis}

Lectin and glycan arrays offer a high-throughput approach for cellular glycoprofiling and the identification of preferential carbohydrate binding moieties, respectively. Thus, to assess the functional consequences of glycogene expression changes in response to HDAC inhibition, total protein from SW13 control cells and SW13 cells that had been treated with $1 \mathrm{nM}$ FK224 for 24h were subjected to lectin and glycan array analysis $(n=4$ per group). Arrays were performed and analyzed by RayBiotech. The Lectin 40 array is designed to detect glycan profiles using 40 unique lectins, while the Glycan 100 array assess carbohydrate binding preferences using the 100 most frequently identified structures showing important binding function in the literature. Lists of all lectins and glycans utilized in the arrays are available in Additional file 1: Tables S1 and S2.

\section{Lectin binding analysis of carbohydrate expression}

Binding of select lectins were validated by lectin blot analysis wherein $25 \mu \mathrm{g}$ total protein from SW13 control or FK228 treated cells was electrophoresed through a pre-cast 4-20\% polyacrylamide gel and then transferred to a PVDF membrane. Membranes were blocked with Pierce SuperBlock ${ }^{\circ}$ buffer for $30 \mathrm{~min}$, and then incubated with $20 \mu \mathrm{g} / \mathrm{ml}$ FITC labeled lectins (EY Laboratories) for $\sim 2 \mathrm{~h}$ before being imaged using a ChemiDoc. Alternatively, treated and untreated cells were fixed as described above before incubation with $20 \mu \mathrm{g} / \mathrm{ml}$ FITC labeled lectins for $\sim 2 \mathrm{~h}$. Samples were mounted with ProLong Gold anti-fade reagent with DAPI to stain nuclei and photographed using a Zeiss Axiovert apotome with a $40 \mathrm{X}$ objective lens and a uniform exposure at each wavelength. To demonstrate specificity of lectin binding, wheat germ agglutinin (WGA) stained cells were incubated with WGA elution buffer for $30 \mathrm{~min}$ for mounting and visualization.

\section{Measuring GAG-sulfation}

Total GAG-sulfation was assayed using a 1,9-Dimethylmethylene blue (DMB) assay as previously described [15]. DMB is a cationic dye that specifically binds to sulfated glycosaminoglycans with an absorbance at $\sim 525 \mathrm{~nm}$. Briefly, $\sim 1 \times 10^{6}$ cells were collected in $40 \mu$ PBS or RIPA buffer. For the cells in PBS, $125 \mu \mathrm{l}$ DMB buffer $(31 \mu \mathrm{M}$ DMB in $55 \mathrm{nM}$ formic acid, $\mathrm{pH} 3.5)$ was added and transferred to a clear-walled 96-well plate. DMB binding was quantified by measuring the optical density at $525 \mathrm{~nm}$. Total protein levels were assessed by BCA assay from the cells in RIPA buffer. DMB binding levels were normalized to total protein levels.

\section{Viability assays}

Chemotherapeutic sensitivity was measured using an MTT (3-(4,5-Dimethylthiazol-2-yl)-2,5-diphenyltetrazolium bromide) assay. Cells were plated at $3 \times 10^{4}$ cells per well in 96-well plates and incubated with 1 , 10 , or $50 \mathrm{nM}$ paclitaxel (Cayman Chemical) for 24 or $48 \mathrm{~h}$. Following treatment, $10 \mu \mathrm{l}$ of $12 \mathrm{mM}$ MTT was added to each well and cells were placed back in the incubator at $37^{\circ} \mathrm{C}$ for $4 \mathrm{~h}$. The formazan was solubilized by adding 100 ul solubilization solution (40\% DMSO, 16\% SDS, $2 \%$ acetic acid) followed by 
another incubation at $37^{\circ} \mathrm{C}$ for $1 \mathrm{~h}$. Spectrometric absorbance at $570 \mathrm{~nm}$ was measured with a microplate reader. Each assay included four technical replicates and was repeated at least three times. Paclitaxel effects at each dose, and differences in paclitaxel response between cell lines were analyzed using a two factor mixed design ANOVA using SPSS version 19 software (Chicago, IL). A Bonferroni test was used to adjust for multiple pairwise comparisons. Mean differences were considered statistically significant at $p<0.05$.

\section{Results}

HDAC inhibition induces morphologic and phenotypic changes in SW13 cells

Previous work has demonstrated that the SW13 cell line can exist at two distinct subtypes, and that subtype determination is epigenetically regulated $[13,14,16]$. One subtype (SW13-) is a rapidly growing, highly tumorigenic, epithelial-like subtype, while this other (SW13+) is a slow growing, metastatic, more mesenchymal-like subtype [14]. The two subtypes are typically distinguished by the presence (SW13+) or absence (SW13-) of the intermediate filament protein vimentin and the expression of the tumor suppressor protein BRM (a subunit of the SWI/SNF chromatin remodeling complex with ATPase activity). HDAC inhibitors have been shown to induce the expression of these proteins $[14,16]$. To evaluate the capacity for HDAC inhibition to influence SW13 subtype phenotype and oncogenic characteristics, SW13 cells were treated with $1 \mathrm{nM}$ FK228 for $24 \mathrm{~h}$, after which morphology, proliferation, and MMP activity were assessed. Figure 1 a shows representative images of control SW13 cell morphology and SW13 cell morphology following treatment with FK228. Under control conditions, the majority of SW13 cells are small, rounded, epithelial cells that tend to grow very rapidly (SW13- phenotype) (Fig. 1 a).

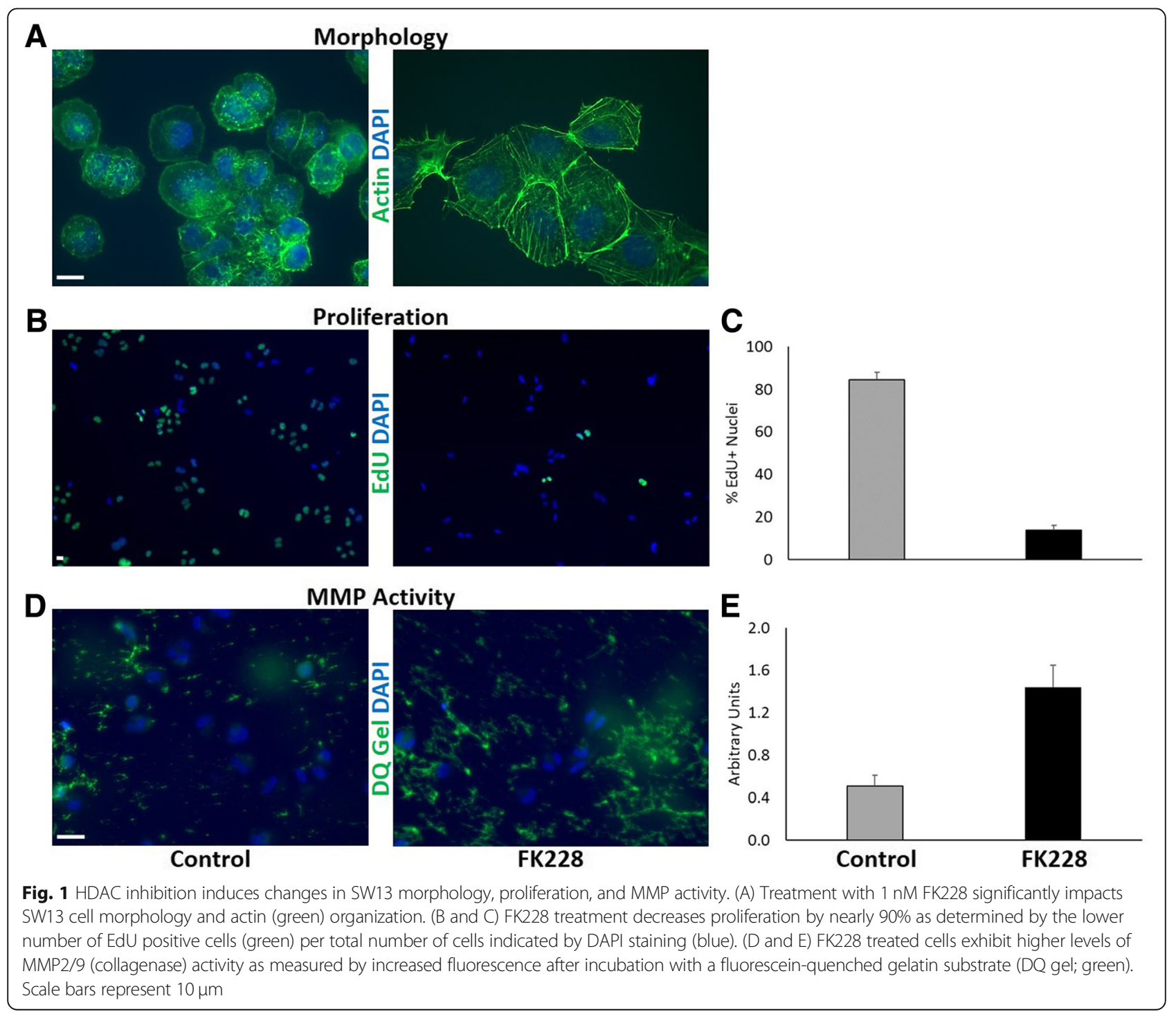


However, treatment with 1 nM FK228 significantly impacts SW13 cell morphology and actin organization (Fig. 1 a), and significantly slows SW13 cell proliferation (Fig. $1 \mathrm{~b}$ and c). FK228 treatment however also significantly increases SW13 cell collagenase activity (Fig. $1 \mathrm{~d}$ and e). Collectively, these results demonstrate that FK228 treatment induces a subtype switch from a rapidly growing, epithelial-like SW13- subtype to a slow growing, but more invasive, mesenchymal-like SW13+ subtype. Interestingly, this phenomenon is not limited to the SW13 cell line. Lin et al. showed similar responses of HDAC inhibitor-induced increased metastatic capacity in 13 other human cell lines, both in vitro and in vivo [9]. Because of the vast interest in using HDAC inhibitors as cancer therapeutics, we were interested in better understanding the mechanisms underlying this type of negative response.

HDAC inhibitor treatment significantly impacts expression of SW13 glycome genes

As a first approach to identifying how HDAC inhibitor treatment can lead to such dramatic changes in oncogenic properties, we performed microarray analyses to assess global gene expression changes in the SW13 cell line following HDAC inhibition. We chose to continue with the SW13 cell line because of its two well defined epigenetic phenotypes, and its well characterized response to HDAC inhibition. First, SW13 cells were treated with $1 \mathrm{nM} \mathrm{FK} 228$ for $24 \mathrm{~h}$, total RNA was isolated, and then submitted for microarray analysis. Following HDAC inhibition, the expression of 1760 genes was increased, while 1490 genes had decreased expression (Additional file 1: Table S3). A gene set enrichment analysis of Gene Ontology (GO) terms was then performed using the differentially expressed gene lists as input. Top enrichment GO terms based on biological processing included negative regulation of cell differentiation, as well as regulation of cell migration and cell proliferation (Additional file 1: Table S4), which were consistent with the phenotypic changes observed in Fig. 1.

Included in the list of differentially expressed genes are enzymes in key pathways affecting the biosynthesis and degradation of most classes of glycolipids and glycoproteins, including enzymes which modify sulfation levels of these molecules (Table 1). Several differentially expressed enzymes are initiators in their respective biosynthetic pathways suggesting that the flux through these pathways may be substantially altered. Affected pathways include EGF domain modification, GPI-anchor biosynthesis, muscin-type O-linked oligosaccharide synthesis, and the core tetrasaccharide linkers of O-linked GAG synthesis (heparan sulfate proteoglycan (HSPG), chondroitin sulfate, and dermatin sulfate). Furthermore, in the chondroitin sulfate and HSPG biosynthetic pathways, the enzymes involved in the initial elongation of the core tetrasaccharide linker are differentially expressed. As over $50 \%$ of all proteins are glycosylated, glycosylation is recognized as the predominant post-translational modification. Thus, shifts in the enzymes which catalyze these modifications may have wide-ranging effects.

Interestingly, $84 \% \quad(43 / 51)$ of the differentially expressed genes identified in this study are involved in glycome biosynthesis and have been linked to cancer (Table 1, highlighted gene symbol entries). Some have been characterized as cancer biomarkers linked to prognosis using clinical data, while others have been shown to affect patterns of oncogenesis in laboratory studies and others to alter sensitivity to chemotherapeutics. This suggests that the observed changes in expression of genes coding for glycolipid and glycoprotein biosynthetic pathways may collectively result in alterations in the oncogenic potential of FK228 treated cells.

\section{Differential expression of HSPG genes and HSPG binding proteins}

In analyzing the differentially expressed genes in Table 1, we noted that FK228 treatment altered the expression of enzymes involved in determining heparan sulfate (HS) chain length and composition. Indeed, more than half (5/ 9) of the enzymes in the HSPG biosynthetic pathway were differentially expressed: xylosyltransferase I (XYLT1) and UDP-Gal:betaGal beta 1,3-galactosyltransferase polypeptide 6 (B3GALT6), which are involved in the synthesis of the core tetrasaccharide linker and exostosin glycosyltransferase 1 (EXT1), N-deacetylase/N-sulfotransferase (NDST1) and Glucuronic acid epimerase (GLCE), which function in the elongation of HSPGs. In addition, differential expression of sulfatases SULF1 and SULF2 suggests that the sulfation of these moieties may be altered with FK228 treatment. Although HSPG function is dependent upon the presence or absence of HSPGs and HSPG binding partners, the vast majority of these interactions are dictated by the presence and composition of HS chains on the HSPG core proteins.

In addition to potential alterations in HS composition, we noted a shift in expression of a significant number of genes coding for HS modified proteins and HSPG binding partners (Table 2). HSPGs can be broken into 3 broad classes based on cellular localization and all classes of HSPGs were affected by HDAC inhibition: membrane (glypicans 2, 3, and 4 and syndecans 1, 2, and 4), extracellular matrix (ECM) (collagens type IX alpha 1 and XII alpha 1, and testican), and secretory (serglycin). We next examined the expression of HSPG binding proteins with FK228 treatment in the microarray data. Notably, the expression of 31 different HSPG binding 
Table 1 Differentially expressed enzymes and their function within the glycome. Enzymes affecting metabolism of glycolipids and glycoproteins whose expression levels change in response to HDAC inhibition are grouped according to their affected pathway and whether the protein product is associated with cancer (are in bold) or is the initial step in the biosynthetic pathway (are in italic). References documenting the gene product link to cancer indicated in parentheses

\begin{tabular}{lll}
\hline Biosynthetic \& other metabolic processes & & \\
\hline Log2 Fold-change & Symbol & Gene Name \\
\hline Multiple Pathways & & \\
-1.26 & FUT10 & $a-(1,3)$-fucosyltransferase $10[46,47]$ \\
-1.26 & FUT11 & $a-(1,3)$-fucosyltransferase $11[46,48,49]$ \\
-1.56 & B4GALT2 & UDP-Gal: $\beta$-GlcNAc $\beta$-(1,4)-galactosyltransferase 2 \\
& & {$[50]$} \\
1.07 & B3GAT2 & $\beta-(1,3)$-glucuronyltransferase 2
\end{tabular}

Glycoprotein

EGF Domain

$-1.04$

1.30

POGLUT1

LFNG

N \& O-Linked Pathways

$$
1.56
$$

B3GNT2

Complex N-Linked Pathway

$\begin{array}{ll}-1.10 & \text { ALG13 } \\ -1.09 & \text { ALG10 } \\ 5.16 & \text { MAN1A1 } \\ 1.63 & \text { MGAT4A }\end{array}$

Complex O-linked Pathway

$-1.28$

GALNT14

1.00

GALNT6

$-1.08$

GALNT7

1.79

GCNT1

O-linked GAG synthesis

Core tetrasaccharide linker for HSPG, Chondroitin Sulfate, Dermatan sulfate

2.85

$-1.36$

XYLT1

B3GALT6

Chondroitin Sulfate

$$
1.85
$$

HSPGS

1.10

$-2.22$

EXT1

NDST1

1.30

GLCE

Glycolipid metabolism

1.07

KDEL1

1.07

KDEL2

Sphingolipid \& Gangliosides (lactosylceramide modification)

1.57

A4GALT

1.46
Protein O-glucosyltransferase 1 [50-53]

O-fucosylpeptide 3- $\beta$-GlcNAc transferase [50, 54]

$\mathrm{N}$-acetyllactosaminide $\beta$-(1,3)-GlcNAc transferase $2[50,55]$

UDP-GlcNAc transferase subunit [50]

a-1,2-glucosyltransferase [56]

a-Mannosidase, class 1A, member $1[8,52]$

$\mathrm{a}-(1,3)$-mannosyl-glycoprotein $4-\beta-N$ acetylglucosaminyltransferase A [50,56]

Polypeptide GalNAc transferase $14[8,57,58]$

Polypeptide GalNAc transferase $6[8,50]$

GalNAc transferase $7[8,50,59,60]$

$\beta$-(1,3)-galactosyl-O-glycosyl-glycoprotein $\beta-1,6$ GlcNAc transferase $[50,61,62]$

Xylosyltransferase I [50,63]

UDP-Gal:ßGal $\beta-(1,3)$-Gal transferase polypeptide 6 (GALT2)

Chondroitin sulfate $\mathrm{N}$-acetylgalactosaminyltransferase 1

Exostosin glycosyltransferase 1 [50]

$\mathrm{N}$-deacetylase/N-sulfotransferase [50]

Glucuronic acid epimerase [64, 65]

KDEL motif-containing protein 1 [50]

KDEL motif-containing protein 2 [50]

a-(1,4)-galactosyltransferase [50]

ST3 $\beta$-galactoside a-(2,3)-sialyltransferase 5 [50] 
Table 1 Differentially expressed enzymes and their function within the glycome. Enzymes affecting metabolism of glycolipids and glycoproteins whose expression levels change in response to HDAC inhibition are grouped according to their affected pathway and whether the protein product is associated with cancer (are in bold) or is the initial step in the biosynthetic pathway (are in italic). References documenting the gene product link to cancer indicated in parentheses (Continued)

\begin{tabular}{lll}
\hline Biosynthetic \& other metabolic processes & & \\
\hline Log2 Fold-change & Symbol & Gene Name \\
\hline 2.80 & ST8SIA1 & $\begin{array}{l}\text { ST8 (a-N-acetyl-neuraminide a-(2,8) } \\
\text { sialyltransferase } 1 \text { ) } \\
\text { ST6 (a-N-acetyl-neuraminyl-2,3- } \beta \text {-galactosyl-1,3) }\end{array}$ \\
$\begin{array}{lll}1.30 & \text { ST6GALNAC3 } & \text { Phosphatidylinositol GlcNAc transferase } \\
1.10 & \text { PIGH } & \text { subunit H [50] } \\
-1.67 & \text { PIGW } & \begin{array}{l}\text { Phosphatidylinositol-glycan biosynthesis class } \\
\text { W protein }\end{array} \\
-1.21 & \text { PIGO } & \begin{array}{l}\text { GPI ethanolamine phosphate } \\
\text { transferase 3 [50] }\end{array} \\
-1.13 & \text { PIGU } & \text { Phosphatidylinositol glycan anchor biosynthesis } \\
\text { class U protein [50] }\end{array}$
\end{tabular}

Polysialic acid

2.71

1.27

Sulfation levels

General enzymes

1.11

$-1.09$

Sulfatases (HSPG)

2.94

1.11

Protein sulfotransferase

1.00

Lipid sulfotransferases - sphingolipid/ceramide 1.38

$\mathrm{N} \& \mathrm{O}$ linked sulfotransferases

1.35

$-1.67$

CHST9

Chondroitin / Dermatan sulfate

1.25

1.05

$-1.42$

2.58

Catabolic enzymes

Lysomal enzymes

1.39

2.80

Glycoprotein Unibiquitin ligases (ERAD pathway)

PAPSS1

SULF1

SULF2

TPST2

CHST14

NEU1

FUCA 1
ST6GAL2 / SIAT2

ST8SIA4 / SIA8D

CHST10

CHST11

CHST12

GAL3ST4
Tyrosylprotein sulfotransferase 2 [50]

Galactose-3-O-sulfotransferase 1 [69, 70]

Carbohydrate ( $\mathrm{N}$-acetylgalactosamine 4-0) sulfotransferase 8

Carbohydrate ( $\mathrm{N}$-acetylgalactosamine 4-0) sulfotransferase 9 [71-73]

3'-phosphoadenosine 5'-phosphosulfate synthase 1 [50]

carbohydrate sulfotransferase 10 [50]

Sulfatase $1[66,67]$

Sulfatase 2 [66-68]

Carbohydrate (chondroitin 4) sulfotransferase 11 (C4ST-1) [50]

Carbohydrate (chondroitin 4) sulfotransferase 12 [50]

Carbohydrate (dermatan 4) sulfotransferase 14

Galactose-3-O-sulfotransferase 4 [50]

Neuraminidase 1 (lysosomal sialidase)

Fucosidase, a-L- 1, tissue [52] 
Table 1 Differentially expressed enzymes and their function within the glycome. Enzymes affecting metabolism of glycolipids and glycoproteins whose expression levels change in response to HDAC inhibition are grouped according to their affected pathway and whether the protein product is associated with cancer (are in bold) or is the initial step in the biosynthetic pathway (are in italic). References documenting the gene product link to cancer indicated in parentheses (Continued)

\begin{tabular}{lll}
\hline Biosynthetic \& other metabolic processes & & \\
\hline Log2 Fold-change & Symbol & Gene Name \\
\hline 1.03 & FBXO2 & F-box only protein 2 [50] \\
-3.01 & FBXO6 & F-box only protein 6 [50] \\
-1.66 & FBXO17 & F-box only protein 17 [50] \\
Metabolic enzymes & & \\
1.67 & GALM & Galactose mutarotase [50] \\
\hline
\end{tabular}

proteins were impacted (24 increased and 7 decreased) by HDAC inhibition. These gene products fall into only a few categories with the most abundant (16 of 31) being related to growth factor or cytokine signaling. In addition, 4 are differentially expressed ECM genes, 3 are adhesive proteins (including REG4 which is a mannose binding lectin), and 4 are proteases or genes which affect protease activity. Collectively, these changes in gene expression might be expected to alter the cellular environment and these changes may further modify growth factor signaling. For example, a highly differentially expressed protein, SERPINE2, has been linked to invasiveness in pancreatic cancer $[17,18]$.

\section{HDAC inhibition alters the expression of HSPGs and related genes}

Next, we quantitated expression of several genes to validate our array data by qPCR (Fig. 2). After treatment with FK228, expression of the HSGPs glypican-3 (GPC3) and serglycin (SRGN) increased by 5 - and 35 -fold respectively (Fig. 2), increases that are in the same direction as the gene chip data (which were 2.85 and 2.78 fold respectively). Although not HSPGs, FGFR1 and FGFR2 function as HSPG co-receptors. As shown in Fig. 2, mRNA levels for fibroblast growth factor receptors FGFR1 and FGFR2 are 2- and 4-fold higher in FK228 treated cells as measured by qPCR. By comparison, in the microarray analysis expression of FGFR2 increases 2.92 fold while expression of FGFR1 does not change significantly. Granulin (GRN), a growth regulatory glycoprotein which promotes cancer progression and which interacts with HS [19], is differentially expressed as measured by qPCR by 5 -fold.

\section{HDAC inhibition decreases cellular GAG-sulfation}

As select genes for both HS modified proteins and their binding partners were differentially expressed, we next asked if the above gene expression changes resulted in detectable alterations in more global changes in the glycome. First, to assess whether the FK228 induced significant increases in the expression of many sulfotransferases had a functional impact on GAG-chain sulfation a DMB binding assay was performed. DMB binding was significantly higher in SW13 cells treated with $1 \mathrm{nM}$ FK228 than in control SW13 cells (Fig. 3 a). These results indicate that total GAG-chain sulfation is significantly increased by HDAC inhibitor treatment. It should be noted that the DMB assay detects all changes in GAG sulfation and that this assay does not distinguish between changes in HSPG sulfation from the other classes of sulfated GAGs including chondroitin, dermatan, and keratan sulfate as well as hyaluronic acid. As sulfotransferases which modify chondroitin and dermatan are differentially expressed (CHST11, CHST12, CHST14), differential sulfation of these GAG structures may contribute to the results of the DMB assay. In addition, sulfation of non-GAG moieties may also be affected by HDAC inhibitor treatment as genes involved in modification of carbohydrates (CHST10), proteins (TPST2), lipids GAL3ST1), and N- and O-linked ST8, CHST9) are also differentially expressed.

\section{Lectin binding detects altered cellular glycan expression after HDAC inhibitor treatment}

Based on the significant impact HDAC inhibition had on the expression of genes involved in GAG-chain sulfation and glycan biosynthesis, we hypothesized that FK228 treatment would also alter the glycosylation pattern of glycoproteins in treated SW13 cells. To test this hypothesis, total protein was isolated from SW13 control cells and SW13 cells treated with $1 \mathrm{nM}$ FK228 for $24 \mathrm{~h}$ and assayed by lectin arrays. Array analysis revealed SW13 cells exhibit significant binding to several lectins when tested in a lectin array (fluorescent intensities $\geq 150 \mathrm{FU}$ ), with highest binding to Vicia villosa (VVA), Hippeastrum hybrid (HHA), and Galanthus nivalis (GNA), respectively, indicative of an abundance of GalNac and $\alpha$ Man containing glycoconjugates (Table 3). Though significant binding to lectins Macckia amurensis 1 (MAA), Eruthrina cristagalli (ECA), and Griffonia Brandeiraea (GS-II) 
Table 2 Differentially expressed heparan sulfate proteoglycans and heparan sulfate binding proteins

\begin{tabular}{|c|c|c|c|}
\hline Category & Gene Symbol & Gene Name & Foldchange \\
\hline \multirow[t]{10}{*}{ Heparan Sulfate Proteoglycans } & COL12A1 & collagen, type XII, alpha 1 & 3.09 \\
\hline & GPC4 & glypican 4 & 2.85 \\
\hline & GPC3 & glypican 3 & 2.78 \\
\hline & SRGN & serglycin & 2.34 \\
\hline & SPOCK1 & $\begin{array}{l}\text { sparc/osteonectin, cwcv and kazal-like domains } \\
\text { proteoglycan }\end{array}$ & 2.10 \\
\hline & GPC2 & glypican 2 & 1.96 \\
\hline & SDC4 & syndecan 4 & 1.23 \\
\hline & SDC2 & syndecan 2 & 1.22 \\
\hline & COL9A1 & collagen, type IX, alpha 1 & 1.20 \\
\hline & SDC1 & syndecan 1 & -1.34 \\
\hline \multirow{31}{*}{$\begin{array}{l}\text { Heparan Sulfate } \\
\text { Proteoglycan } \\
\text { Binding Proteins }\end{array}$} & SERPINE2 & serpin family E member 2 & 4.10 \\
\hline & BMP4 & bone morphogenetic protein 4 & 3.95 \\
\hline & THBS1 & thrombospondin 1 & 3.73 \\
\hline & ADAMTS15 & $\begin{array}{l}\text { ADAM metallopeptidase with thrombospondin type } \\
1 \text { motif, } 15\end{array}$ & 3.58 \\
\hline & Laminin & laminin, beta 1 & 3.49 \\
\hline & LPL & lipoprotein lipase & 3.44 \\
\hline & CCL2 & chemokine ( $\mathrm{C}-\mathrm{C}$ motif) & 3.35 \\
\hline & SFRP1 & secreted frizzled-related protein 1 & 3.25 \\
\hline & LAMA1 & laminin, alpha 1 & 3.16 \\
\hline & FGFR2 & fibroblast growth factor receptor 2 & 2.92 \\
\hline & FSTL1 & follistatin-like 1 & 2.62 \\
\hline & NAV2 & neuron navigator 2 & 2.42 \\
\hline & PGF & placental growth factor & 2.31 \\
\hline & CYR61 & cysteine-rich, angiogenic inducer, 61 & 1.93 \\
\hline & ANOS1 & anosmin 1 & 1.77 \\
\hline & FGF12 & fibroblast growth factor 12 & 1.64 \\
\hline & REG4 & regenerating islet-derived family, member 4 & 1.56 \\
\hline & HBEGF & heparin-binding EGF-like growth factor & 1.44 \\
\hline & TGFBR3 & transforming growth factor, beta receptor III & 1.42 \\
\hline & WNT4 & wingless-type MMTV integration site family, member 4 & 1.38 \\
\hline & FBN1 & fibrillin 1 & 1.30 \\
\hline & $\mathrm{LIPH}$ & lipase, member $\mathrm{H}$ & 1.16 \\
\hline & NCAM & neural cell adhesion molecule 1 & 1.15 \\
\hline & COL5A3 & collagen, type $V$, alpha 3 & 1.05 \\
\hline & FGF10 & fibroblast growth factor 10 & -2.37 \\
\hline & HDGF & hepatoma-derived growth factor & -1.51 \\
\hline & FGF2 & fibroblast growth factor 2 (basic) & -1.20 \\
\hline & ZNF146 & zinc finger protein 146 & -1.19 \\
\hline & AGER & advanced glycosylation end product-specific receptor & -1.18 \\
\hline & PCOLCE2 & procollagen C-endopeptidase enhancer 2 & -1.16 \\
\hline & PCSK6 & proprotein convertase subtilisin/kexin type 6 & -1.09 \\
\hline
\end{tabular}




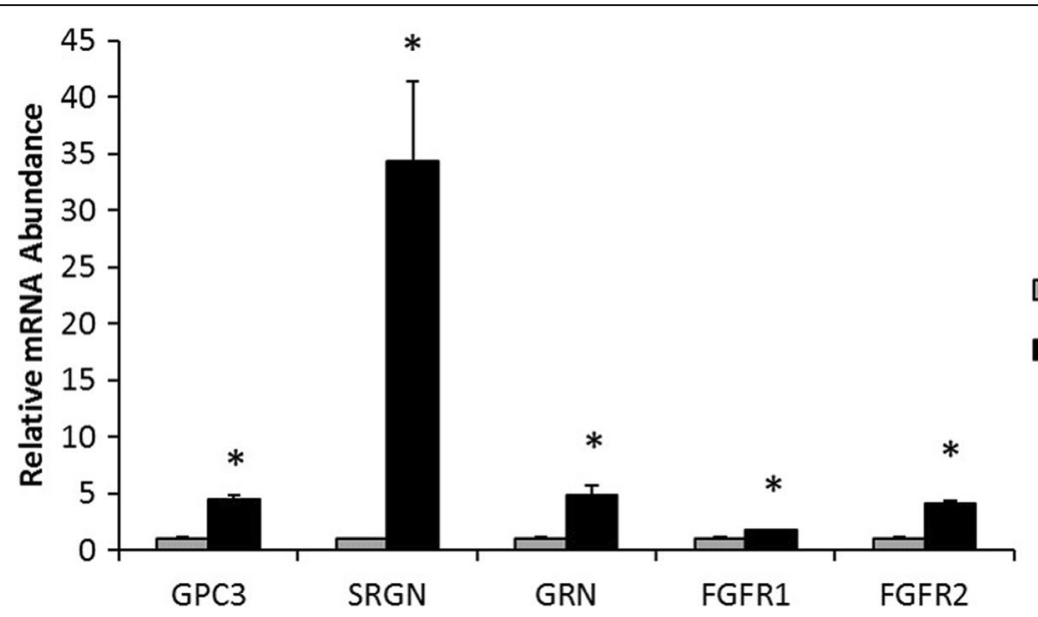

Fig. 2 The expression of HSPGs and related growth factors are in HDAC inhibitor treated SW13 cells. Relative mRNA expression of glypican-3 (GPC3), serglycin (SRGN), granulin (GRN), and fibroblast growth factor receptor (FGFR) 1 and 2, in SW13 cells following treatment with 1 nM of the HDAC inhibitor FK228 for 24. *Denotes statistical difference from control, $p<0.05$

suggests the presence of $\beta$ GlcNac containing conjugates, 8 of the 17 lectins tested for which no binding was detected are also recognized by GlcNAc containing conjugates. This suggests an increased abundance of glycoconjugates with terminal $\beta$ GlcNAc residues (Table 3 and Additional file 1: Table S2). FK228 treatment significantly increased binding to lectins Con A and GNA, while significantly decreasing binding to lectins Artocarpus integrefolia (AIA), Erithrina crstagalli (ECA), Griffonia simplifcifolia I (GS-I), Lotus tetragonolobus (Lotus), Maclura pomifera (MPL), and Vicia faba (VFA) (Fig. 3 b).

Differential binding of select lectins was confirmed via lectin blot analysis (Fig. 3 c), an analysis which also assesses the molecular weights of glycosylated proteins. As seen in the array, FK228 treatment significantly increased the SW13 protein binding affinity for ConA, while it decreased the binding affinity for AIA, ECA, GS-I, Lotus and the profile of labeled proteins appears different after treatment (Fig. 3c). Dolichos biflorus (DBA) and Ulex europaes I (UAE-I) were included as negative controls, and also confirmed the lack of differential binding observed in the lectin array (Table 2 and Fig. 3 b). We noted that bands of different molecular weight were labeled with treatment in multiple lectin blots.

To expand on lectin array and blot data, we also analyzed lectin binding in fixed, cultured cells (Fig. 4). As many of the differentially expressed glycome genes are biosynthetic enzymes which act on both glycolipids and glycoproteins, we analyzed both permeabilized and unpermeabilized cultures. With detergent permeabilization, many glycolipids are extracted so that permeabilized cultures represent glycoprotein-rich samples while unpermeabilized cultures assess both glycolipids and glycoproteins. With this sample preparation, staining with ConA appears unchanged but GS-I and ECA labeling increase. These findings differ from the lectin array in relative intensities and direction of change. Interestingly, there was differential binding of WGA in the fixed samples. The WGA binding was effectively competed with competing sugar binding. We also assessed the binding of the sialic acid directed lectin LPA as genes related to sialic acid were differentially expressed (ST3GAL5, ST8SIA1, ST6GALNAC3, ST6GAL2, ST8SIA4, and NEU1). As shown in Fig. 4, normalized LPA binding increases 8.3-fold after $24 \mathrm{~h}$ of FK228 treatment in cells that have not been permeabilized $(p=0.033)$. However, this differential binding is not seen when cells are permeabilized before lectin binding. These data are supported by the observation that sialic acid is preferentially found in glycolipids [20].

\section{HDAC inhibitor treatment influences cellular expression of glycan binding proteins}

Many of the biological effects of glycans are dependent upon their recognition by glycan binding proteins. Therefore, we next asked if the activity of glycan binding proteins was influenced by FK228 treatment. Of the 100 glycans tested in the array, significant binding (fluorescent intensities $\geq 150 \mathrm{FU}$ ) to 60 glycans was detected in SW13 control protein samples (Table 4, Additional file 1: Table S2). Treatment with $1 \mathrm{nM}$ FK228 for $24 \mathrm{~h}$ significantly increased interactions of SW13 proteins with the aminoglycoside Neomycin trisulfate, and the monosaccharide $\alpha$-Rha-Sp. However, FK228 treatment significantly decreased binding affinities for multiple other classes of glycans including two amino glycosides (geneticin disulfate and neomycin trisulfate), two disaccharides (Glc- $\alpha-1,2-G a l-\alpha-S p$ and 


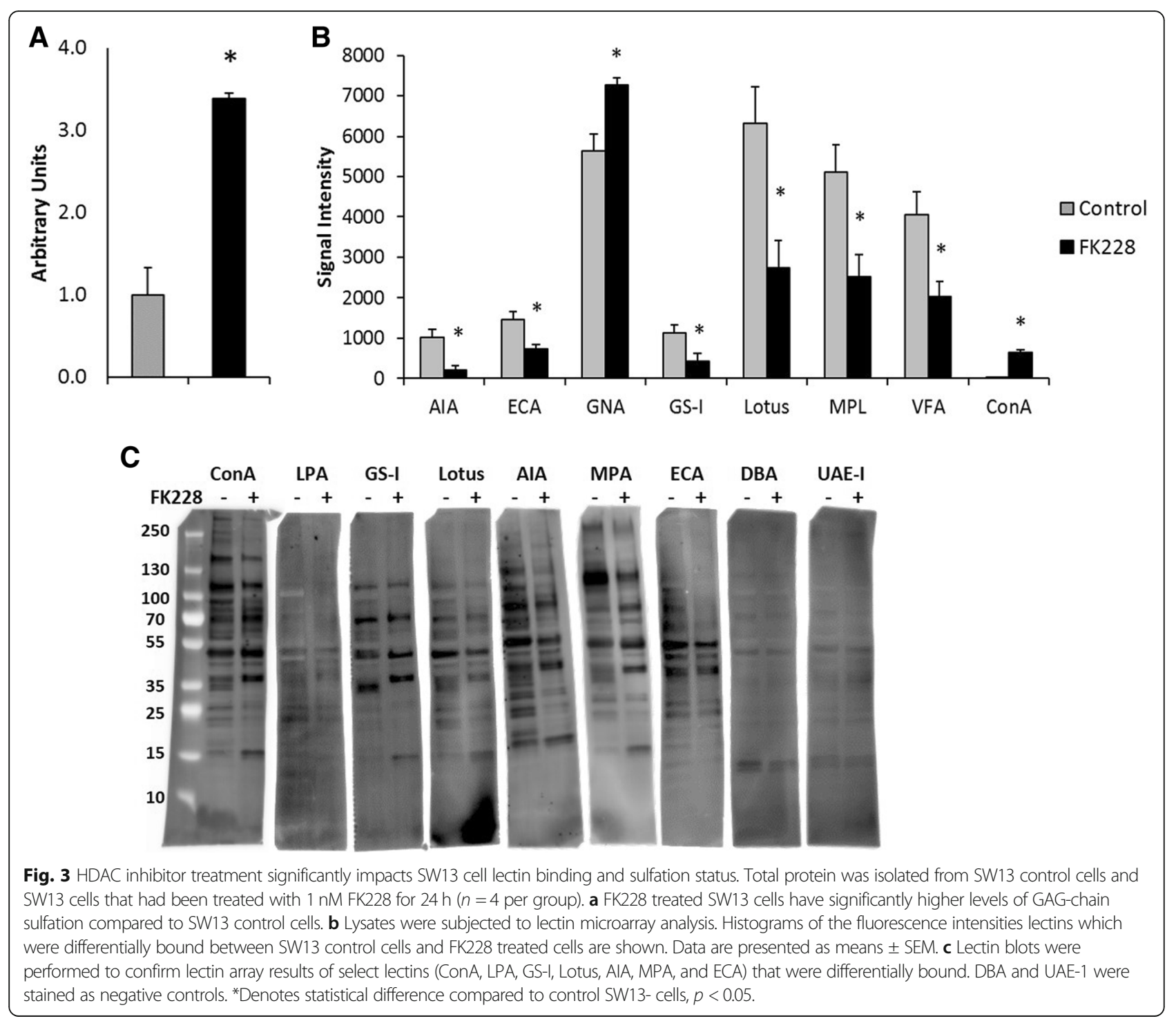

GlcNAc- $\beta-1,2-$ Man- $\alpha$-Sp), one fucosylated oligosaccharide (GalNAc- $\alpha-1,3$-(Fuc- $\alpha-1,2)$-Gal- $\beta-1,4-G l c-\beta$-Sp1), three sialylated oligosaccharides (Neu5Ac- $\alpha-2,8-\mathrm{Neu} 5 \mathrm{Ac}-\alpha-2,8-$ Neu5Ac- $\alpha-2,3-$ Gal- $\beta-1,4-G l c-\beta-S p 3$, Neu5Ac- $\alpha-2,8$-Neu 5 Gc- $\alpha-2,3-G a l-\beta-1,4-$ Glc- $\beta-S p$, and Gal- $\beta-1,3-(\mathrm{Neu} 5 \mathrm{Ac}-$ $\alpha-2,6)-$ GalNAc- $\beta-S p$ ), and two natural oligosaccharides (Maltotetraose- $\beta$-Sp1 and Maltoheptaose- $\beta$-Sp1). Differences in binding interactions observed between SW13 control and FK228 treated samples are illustrated in Table 4.

\section{HDAC inhibitor pre-treatment promotes chemotherapeutic resistance}

HDAC inhibitors are rarely effective as single agents, and are often used in combination with some other type of epigenetic agent or chemotherapeutic. However, changes in proteoglycan expression, glycosylation, and composition can also influence chemosensitivity and chemoresistance [7, 21, 22]. To assess how HDAC inhibitor treatment might impact the SW13 cell response to chemotherapeutic treatment, an MTT assay was used to evaluate the sensitivity of cells to paclitaxel treatment. Paclitaxel was chosen because SW13 cells are not sensitive to cisplatin or doxorubicin [23-25]. Cells were first cultured without treatment or with $1 \mathrm{nM}$ FK228 for $24 \mathrm{~h}$. After $24 \mathrm{~h}$, both control and the FK228 treated cells were plated in fresh media containing no treatment (Control), or $1 \mathrm{nM}, 10 \mathrm{nM}$, or $50 \mathrm{nM}$ paclitaxel for 24 or $48 \mathrm{~h}$. Neither the control SW13 cells nor the SW13 cells that had been treated with FK228 were affected by the $24 \mathrm{~h} 1 \mathrm{nM}$ paclitaxel treatment (Fig. 5 a). However, the metabolic activity of control SW13 cells was significantly decreased compared to the FK228 pre-treated SW13 cells following $24 \mathrm{~h}$ of treatment with both $10 \mathrm{nM}$ 
Table 3 Comparison of lectin binding affinities between control and FK228 treated SW13 cells

\begin{tabular}{|c|c|c|c|}
\hline Lectin & Known Specificity & Control & FK228 \\
\hline $\mathrm{AAL}$ & Fuca6GIcNAc & & \\
\hline PSA & aMan, $\alpha$ Glc & & \\
\hline UEA-I & $\alpha$ Fuc & & \\
\hline Con A & aMan, $\alpha \mathrm{Glc}$ & & \\
\hline AlA & $\alpha \mathrm{Gal}$ & & \\
\hline GS-I & $\alpha G a l, \alpha G a l N A c$ & & \\
\hline MAA & Galß4GIcNAc & & \\
\hline BPA & Galß3GalNAc & & \\
\hline ECA & Galß4GIcNAc & & \\
\hline LcHA & aMan, $\alpha$ Glc & & \\
\hline ASA & aMan & & \\
\hline WFA & GalNAc & & \\
\hline GS-II & $\alpha$ or $\beta$ GIcNAc & & \\
\hline DBA & $\alpha$ GalNAc & & \\
\hline NPA & aMan & & \\
\hline $\mathrm{ACL}$ & Galß3GalNAc & & \\
\hline VFA & aMan & & \\
\hline SJA & $\beta$ GalNAc & & \\
\hline MPL & Galß3GalNAc & & \\
\hline EEL & Gala3Gal & & \\
\hline GNA & aMan & & \\
\hline $\mathrm{HHA}$ & aMan & & \\
\hline Lotus & $\alpha$ Fuc & & \\
\hline VVA & GalNAc & & \\
\hline
\end{tabular}

Relative Fluorescent Units

$0-500 \quad 500-1000 \quad 1000-2000 \quad 2000-5000 \quad>5000$

Representative fluorescent signal intensities for binding to lectins of various glycan specificities of SW13 control cells and SW13 cells treated with $1 \mathrm{nM}$ FK228 for $24 \mathrm{~h}$. Fuc: L-Fuctose; Gal: D-Galactose; GalNac: N-Acetylgalactosamine; Glc: D-glucose; GlcNAc: N-Acetylglucosamine; Man: Mannose

and $50 \mathrm{nM}$ paclitaxel (Fig. 5 a). Similar patterns held true following $48 \mathrm{~h}$ of paclitaxel treatment, with no significant effect on metabolic activity in either the control or FK228 pre-treated SW13 cells at the $1 \mathrm{nM}$ paclitaxel dose, but significant decreases in metabolic activity in both the control and FK228 treated cells at the $10 \mathrm{nM}$ and $50 \mathrm{nM}$ doses (Fig. 5 b). Of importance however, is that the metabolic activity of FK228 pre-treated cells was impacted significantly less than that of control cells in response to paclitaxel treatment at both the $10 \mathrm{nM}$ (26\% vs $49 \%$ ) and $50 \mathrm{nM}$ (48\% vs $71 \%)$ doses (Fig. 5 b).

\section{Discussion}

Data presented here suggests that HDAC inhibitor treatment of SW13 cells leads to $>2$ fold changes in the expression of 3250 genes, a substantial portion of the genome. In our effort to characterize some of the additional functional consequences of HDAC inhibitor treatment, we documented significant impacts on SW13 cell morphology, growth, invasiveness, and chemotherapeutic response after HDAC inhibition. Importantly, these findings are not unique to the SW13 cell line, as numerous cell types have been shown to exhibit similar dramatic changes in gene expression and phenotypic characteristics with alterations in the glycome $[9,26,27]$. In addition, multiple HDAC inhibitors (including changes valporic acid, sodium butyrate, apicidin, MS-275, SAHA, and TSA) are able to illicit similar phenotypic changes in multiple cell lines [9]. Thus, we were confident SW13 cells and their response to FK228 treatment were a relevant model to investigate how HDAC inhibitor treatment contributes to such dichotomous epigenetically and phenotypically distinct oncogenic states. 
Table 4 Comparison of glycan binding affinities between control and FK228 treated SW13 cells

\begin{tabular}{|c|c|c|c|}
\hline Core Structure & Glycan & Control & FK228 \\
\hline \multirow[t]{6}{*}{ Aminoglycosides } & Kanamycin sulfate & & \\
\hline & Geneticin Disulfate Salt (G418) & & \\
\hline & Tobramycin & & \\
\hline & Sisomicin Sulfate & & \\
\hline & Gentamicin Sulfate & & \\
\hline & Neomycin trisulfate & & \\
\hline \multirow[t]{8}{*}{ Disaccharides } & Glc- $\alpha-1,2-G a \mid-\alpha-S p$ & & \\
\hline & GalNAc- $\beta-1,4-G \mid c N A c-\beta-S p 2$ & & \\
\hline & Gal- $\alpha-1,3-G a l-\beta-S p 1$ & & \\
\hline & Gal- $\beta-1,4-(6 S)$ GINAc- $\beta-S p$ & & \\
\hline & Gal- $\beta-1,3-G a l N A c-\beta-S p 1$ & & \\
\hline & Glc- $\alpha-1,4-G \mid c-\beta-S p 1$ & & \\
\hline & GlcNAc- $\beta-1,2-$ Man- $\alpha-S p$ & & \\
\hline & GIcNAc- $\beta-1,6-G \mid c N A c-\beta-S p$ & & \\
\hline \multirow{3}{*}{$\begin{array}{l}\text { Fucosylated } \\
\text { Oligosaccharides }\end{array}$} & Neu5Gc- $\alpha-2,6-G a l-\beta-1,3-G l c N A c-\beta-S p$ & & \\
\hline & $\begin{array}{l}\text { GalNAc- } \alpha-1,3-(\text { Fuc- } \alpha-1,2)-G a l-\beta-1,4-G l c-\beta-\text { [Blood A antigen } \\
\text { tetrose]-Sp1 }\end{array}$ & & \\
\hline & $\begin{array}{l}\text { Gal- } \beta-1,3-(\text { Fuc- } \alpha-1,4)-G l c N A c-\beta-1,3-G a l-\beta-1,4-(\text { Fuc- } \alpha-1,4)- \\
\text { Glc- } \beta \text { - [Lewis A]-Sp1 }\end{array}$ & & \\
\hline \multirow{5}{*}{$\begin{array}{l}\text { Gangliosides and } \\
\text { Sialylated } \\
\text { Oligosaccharides }\end{array}$} & Neu5Ac- $\alpha-2,6-(N e u 5 A c-\alpha-2,3)-G a l-\beta-1,3-G a I N A c-\beta-S p$ & & \\
\hline & Neu5Ac- $\alpha-2,8-$ Neu5Ac- $\alpha-2,6-$ Gal- $\beta-1,4-$ Glc-Sp5 & & \\
\hline & $\begin{array}{l}\text { Neu5Ac- } \alpha-2,8-\text { Neu5Ac- } \alpha-2,8-N e u 5 A c-\alpha-2,3-G a l-\beta-1,4-G l c-\beta- \\
\text { Sp3 }\end{array}$ & & \\
\hline & Neu5Ac- $\alpha-2,8-N e u 5 G c-\alpha-2,3-G a l-\beta-1,4-$ Glc- $\beta-S p$ & & \\
\hline & Gal- $\beta-1,3-($ Neu5Ac- $\alpha-2,6)-G a I N A c-\beta-S p$ & & \\
\hline \multirow[t]{5}{*}{ Globo Series } & GlcNAc- $\beta-1,3-$ Gal- $\beta-1,4-G \mid c-\beta-S p$ & & \\
\hline & Gal- $\alpha-1,4-G a l-\beta-1,3-G I c N A c-\beta-S p$ & & \\
\hline & Gal- $\alpha-1,4-G a l-\beta-1,4-G l c N A c-\beta-S p 1$ & & \\
\hline & GalNAc- $\beta-1,3-G a l-\alpha-1,4-G a l-\beta-1,4-G \mid c-\beta-S p$ & & \\
\hline & GalNAc- $\beta-1,3-G a l-\beta-1,4-G \mid c-\beta-S p$ & & \\
\hline \multirow[t]{5}{*}{ Monosaccharides } & $\beta-D-R h a-S p$ & & \\
\hline & $\beta$-Glc-Sp & & \\
\hline & $\beta$-Gal-Sp & & \\
\hline & $\beta$-D-GlcA-Sp & & \\
\hline & $\alpha-R h a-S p$ & & \\
\hline \multirow{2}{*}{$\begin{array}{l}\text { Natural } \\
\text { Oligosaccharides }\end{array}$} & Maltotetraose- $\beta-S p 1$ & & \\
\hline & Maltoheptaose- $\beta-S p 1$ & & \\
\hline O-, N-glycans & Gal- $\alpha-1,3-$ Gal- $\beta-1,3-G I c N A c-\beta-S p$ & & \\
\hline
\end{tabular}

Relative Fluorescent Units

$0-500 \quad 500-1000 \quad 1000-2000 \quad 2000-5000 \quad>5000$

Representative fluorescent signaling intensities summarizing the most intense glycan binding interactions for SW13 control cells and SW13 cells treated with $1 \mathrm{nM}$ FK228 for 24 h. Fuc: L-Fuctose; Gal: D-Galactose; GalNac: N-Acetylgalactosamine; Glc: D-glucose; GlcNAc: N-Acetylglucosamine; Man: Mannose

Though in this study we used an HDAC inhibitor which primarily targets HDAC1, it is notable that multiple HDAC inhibitors have been demonstrated to lead to the characteristic phenotypic switch observed in the SW13 cell type $[9,13,14,16]$. Thus, these phenotypic changes are likely not dependent on inhibition of a specific HDAC, but are likely mediated by widespread alterations in the acetylome that subsequently impacts global cellular gene expression. As inhibitors of lysine deacetylation however, HDAC inhibitor treatment 


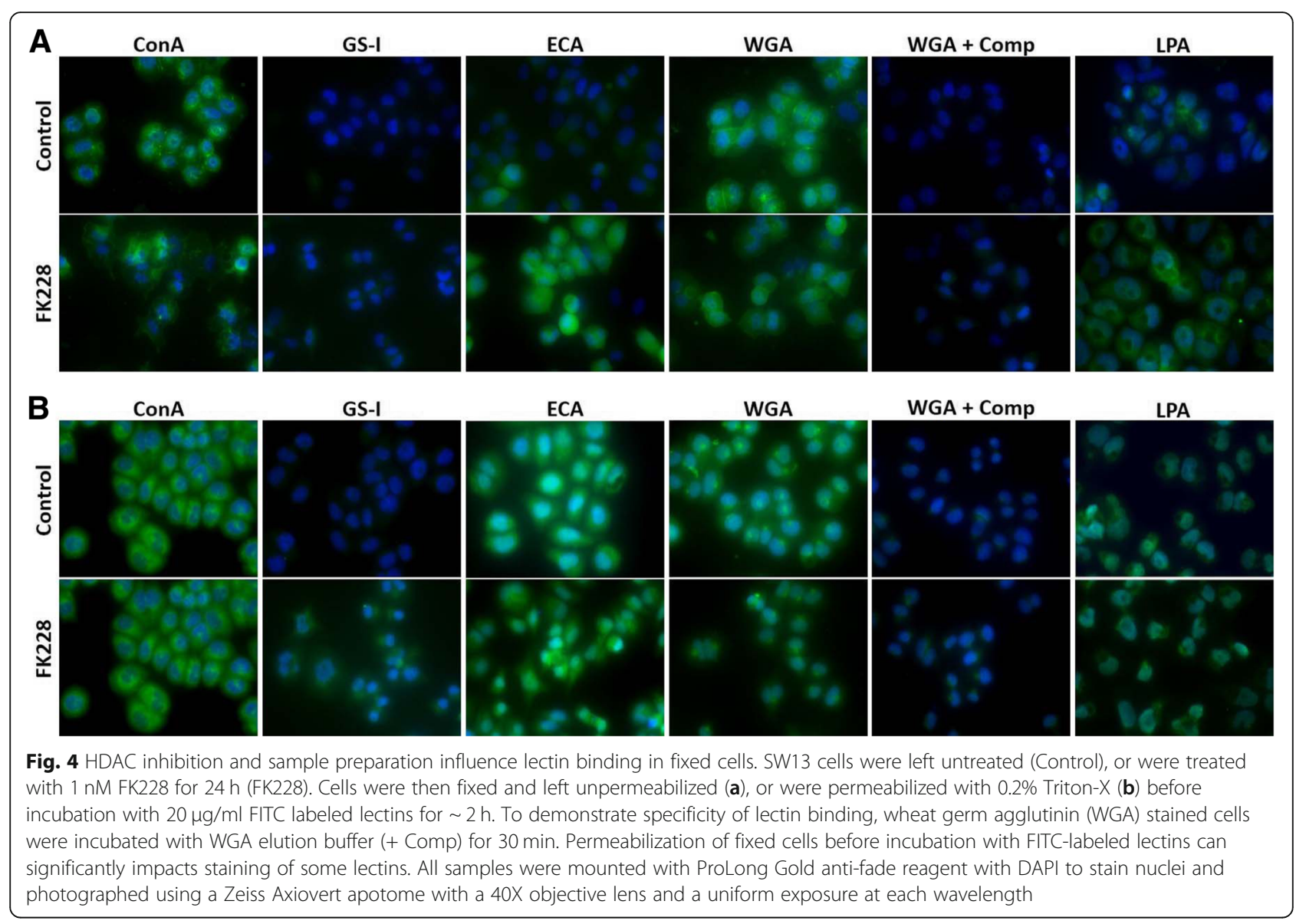

affects the activity of many acetylated proteins, including many non-histone targets. Interestingly, only 3.9\% of the acetylation sites detected after FK228 treatment of a colon cancer cell line were on core histones [28]. Recent work has demonstrated that acetylation patterns are tissue specific and have distinct subcellular distribution [29] and these patterns have been linked to changes metabolism and to regulate a wide variety of biological functions [28, 30,31] and more importantly, acetylation of non-histone proteins has been linked to alterations in gene expression [32, 33]. Amongst the effects of alterations in the acetylome, we have chosen to address the effects of the glycome due to as recent data has suggested that the aberrant glycosylation seen in cancer is epigenetically regulated [34, 35].

Bioinformatics analyses of the microarray suggests that many glycome-related genes are differentially expressed after HDAC inhibitor treatment and many glycosylation pathways appear to be affected by treatment. Among the affected pathways, we found the prevalence of differentially expressed HSPG-related genes in the microarray data notable due to the link of these gene products with oncogenesis. Based on the data presented here, we suggest that HDAC inhibitor- mediated epigenetic regulation of the glycome, and possibly the HPSGs and their biosynthetic machinery, is an important contributory factor to the prevention and progression of oncogenesis.

Given the broad spectrum of differential expression of genes involved in glycome biosynthesis, alterations in lectin binding might be expected and lectin array analysis does indeed demonstrate HDAC inhibition significantly impacts the glycosylation signature of SW13 cell. We found it interesting that the profile of glycosylated proteins recognized by several lectins was also altered. This suggests alterations both in the amount and type of glycosylation, and that these glycan structures are attached to proteins of different molecular weights. Of particular interest is the increase in labeling by the sialic acid binding lectin LPA as increase in this glycosylation is associated with more aggressive tumors [26, 27]. In addition, the fact that this differential binding is not seen when cells are permeabilized underscores need to carefully consider sample preparation when comparing different lectin assays. Specifically, cellular glycosylation is most closely associated with membrane lipids and proteins and these glycans are susceptible to extraction 

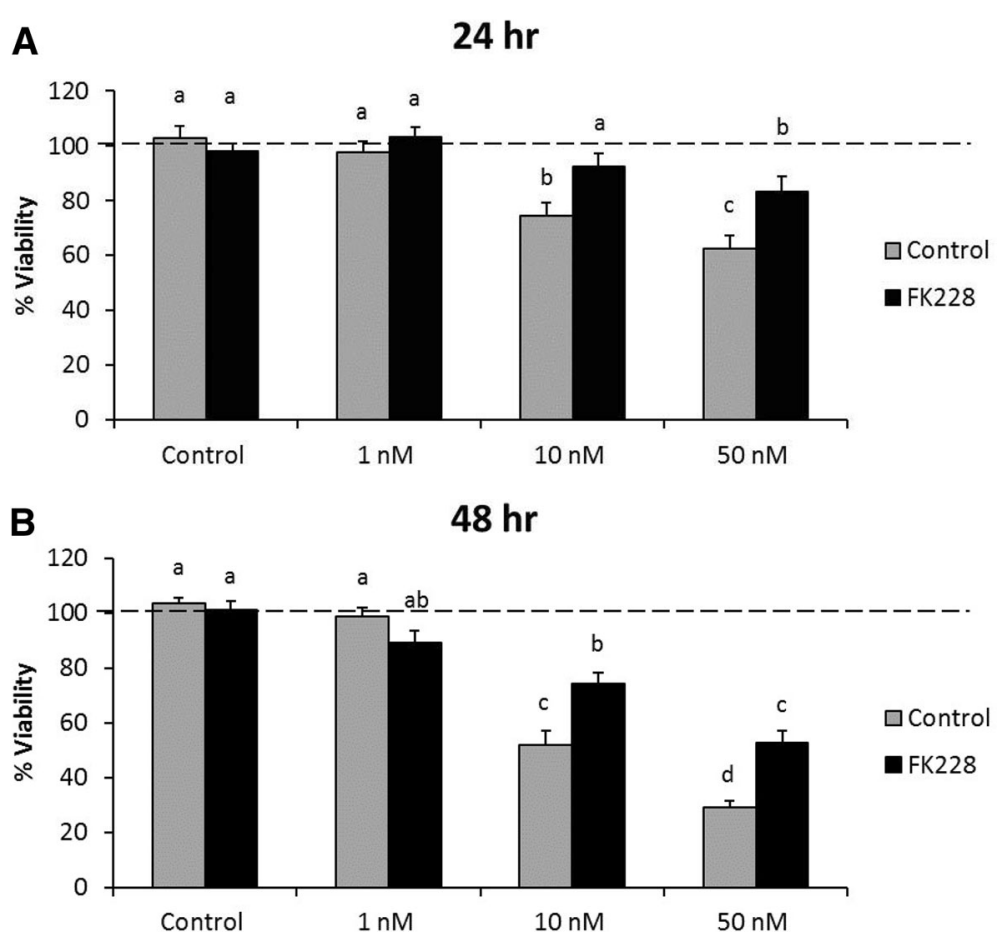

Fig. 5 HDAC inhibitor treatment promotes paclitaxel resistance in SW13 cells. SW13 cells were left untreated (Control), or were treated with 1 nM FK228 for $24 \mathrm{~h}$ (FK228). After, 24 h, FK228 was removed, and control SW13 cells and FK228 pre-treated cells were plated into 96 well plates and left untreated (Control), or were treated with $1 \mathrm{nM}, 10 \mathrm{nM}$, or $50 \mathrm{nM}$ paclitaxel for (a) $24 \mathrm{~h}$ or (b) $48 \mathrm{~h}$. Cell viability was assessed using an MTT assay. Data are presented as means $\pm \mathrm{SEM}$, and are representative of three independent experiments. Superscripts denote statistical significance, $p<0.05$. Treatments that share the same superscripts are not significantly different

with detergent permeabilization. In addition, it is clear that some cytosolic and nuclear proteins are glycosylated and can be bound by lectins (e.g. WGA and UEA) [36, 37] and these proteins may be enriched relative to other proteins due to sample preparation methods.

Importantly, changes in lectin binding corresponded with changes in mRNA expression identified in the microarray, and demonstrate the functional impact of HDAC inhibitor-mediated glycogene expression. For example, expression of the sialylatransferases ST6Gal2 and ST3GAL5 were significantly increased in HDAC inhibitor treated SW13 cells. Sialyltransferases function by linking sialic acids to terminal GalNAc and GlcNAc sugar residues on glycoproteins, and play important roles in cancer progression [38]. Decreased ECA and GS-II binding in HDAC inhibitor treated SW13 cells indicates increased masking of GlcNAc residues, consistent with increased sialyltransferase activity. In-line with our results here, this pattern of activity has also been associated with increased invasive capacity [27].

Similarly, decreased binding to ECA, as well ConA, has also been observed in mammary gland epithelial cells going through TGF $\beta$ induced epithelial to mesenchymal transition, which is also associated with cancer metastasis [39]. Moreover, these changes in lectin binding were also associated with similar changes in $\mathrm{N}$-glycan-related gene expression changes observed in our study as well. Thus, it is interesting to note decreased binding to both of those lectins in response to HDAC inhibitor treatment. VFA binding was also decreased in the HDAC inhibitor treated cells. Intriguingly, treatment with VFA has been demonstrated to decrease the malignant phenotype in other cell lines [40]. Consequently, the identification of different patterns glycogene expression and lectin binding properties of HDAC inhibitor treated cells may play an important role in the development of innovative combinatorial approaches to cancer therapies.

Biological activity of the glycome is also dependent on the recognition of glycans by glycan binding proteins. SW13 cells exhibited binding to a broad number of glycan binding proteins in each of the eight classes present in the array. FK228 treatment significantly impacted the binding affinity for a number of glycans, but of particular interest was the 2-fold increase in $\alpha$-Rha binding. Human serum contains an abundance of anti-carbohydrate antibodies, and anti-Rha antibodies are among the most abundant [41]. Further, rhamnose glycoconjugates have been demonstrated to target anti-carbohydrate antibodies specifically to tumor cells 
prompting rigorous investigations into their use for cancer immunotherapies, with very promising results [41-43]. Our findings that HDAC inhibitor treatment further increases the binding affinity for $\alpha$-Rha raises the exciting possibility to use HDAC inhibitors as enhancers of cancer immunotherapy efficacy.

As mentioned above, HDAC inhibitors have largely proved ineffective as monotherapies for solid tumors, but have had some limited demonstrated efficacy in combination with other agents such as carboplatin and paclitaxel $[44,45]$. In contrast, we observed decreased responsiveness to paclitaxel treatment following HDAC inhibition. It is worth noting that alterations in glycogene expression and cellular glycosylation patterns can significantly impact chemosensitivity $[2,4,5]$. Indeed, increased expression of ST8SIA4 in human leukemia and decreased expression of B4GALT2 in breast cancer cells has been associated with multidrug resistance $[4,5]$. In SW13 cells, we noted both an increase in ST8SIA4 expression and a decrease in B4GALT2 expression in response to HDAC inhibition, which could help explain their decreased sensitivity to paclitaxel treatment. Findings from these studies underscore the importance of glycomic alterations in the progression of cancer and their utility in identification of effective chemotherapeutics. The utility of B4GALT2 and ST8SIA4 as prognostic indicators for HDAC inhibitor treatment effectiveness and chemotherapeutic sensitivity should be further investigated.

\section{Conclusions}

HDAC inhibition substantially alters glycogene expression and significantly influences both glycan and glycan binding protein expression and most of these genes are related to oncogenesis. Importantly, the changes identified by the lectin and glycan arrays are consistent with a metastatic glycosignature and a more aggressive phenotype. Interaction between glycans and glycan binding proteins is key to the function of the dense layer of glycoconjugates on the cellular surface and both types of molecules are affected by HDAC inhibition. As such, we suggest that these changes in combination may result in substantial alterations oncogenic capacity observed in SW13 following after HDAC inhibitor treatment. The capacity for HDAC inhibition to mediate such widespread glycomic alterations in other cell lines remains to be determined. However, given the widespread use of HDAC inhibitors in cancer research, and yet their still limited utility as chemotherapeutic agents in solid tumors continued investigations are warranted.

\section{Additional file}

Additional file 1: Table S1. Table S2. Table S3. Table S4. (ZIP $16600 \mathrm{~kb})$

\section{Abbreviations}

5-Azd-dc: 5-Aza-2'-deoxycytidine; Gal: Galactose; GalNac : N-Acetylgalactosamine; Glc: Glucose; GlcNac: N-Acetylglucosamine; HDAC: Histone deacetylase; Neu: Neuraminic acid; Neu5Ac: N-Acetylneuraminic acid; Neu5Gc: N-

Glycolylneuraminic acid

\section{Acknowledgements}

We thank Agnes Pascual for her technical assistance.

Funding

Midwestern University intramural funds provided to EEH supported this research.

Availability of data and materials

Microarray data may be requested from the corresponding author.

\section{Authors' contributions}

MRM performed the majority of the experiments. Both EEH and MRM analyzed data and wrote parts of the manuscript. Both authors read and approved the final manuscript.

Ethics approval and consent to participate

Not applicable.

Consent for publication

Not applicable.

Competing interests

The authors do not have any competing interests.

\section{Publisher's Note}

Springer Nature remains neutral with regard to jurisdictional claims in published maps and institutional affiliations.

\section{Author details}

${ }^{1}$ College of Human Sciences, Oklahoma State University, Stillwater, OK 74078, USA. ${ }^{2}$ Biomedical Sciences Program, College of Graduate Studies, Midwestern University, Glendale, AZ 85308, USA.

Received: 25 July 2018 Accepted: 23 November 2018

Published online: 16 January 2019

References

1. Guo R, et al. Glycogenes mediate the invasive properties and chemosensitivity of human hepatocarcinoma cells. Int J Biochem Cell Biol. 2013;45(2):347-58

2. Peiris D, et al. Cellular glycosylation affects Herceptin binding and sensitivity of breast cancer cells to doxorubicin and growth factors. Sci Rep. 2017;7:43006.

3. Pinho SS, Reis CA. Glycosylation in cancer: mechanisms and clinical implications. Nat Rev Cancer. 2015;15(9):540-55.

4. Zhang Z, et al. Glycomic alterations are associated with multidrug resistance in human leukemia. Int J Biochem Cell Biol. 2012;44(8):1244-53.

5. $\mathrm{Ma} \mathrm{H}$, et al. Functional roles of glycogene and $\mathrm{N}$-glycan in multidrug resistance of human breast cancer cells. IUBMB Life. 2013;65(5):409-22.

6. Anugraham $M$, et al. Specific glycosylation of membrane proteins in epithelial ovarian cancer cell lines: glycan structures reflect gene expression and DNA methylation status. Mol Cell Proteomics. 2014;13(9):2213-32.

7. Greville $\mathrm{G}$, et al. Epigenetic regulation of glycosylation and the impact on chemo-resistance in breast and ovarian cancer. Epigenetics. 2016; 11(12):845-57.

8. Vojta A, et al. Glyco-genes change expression in cancer through aberrant methylation. Biochim Biophys Acta. 2016;1860(8):1776-85.

9. Lin KT, et al. HDAC inhibitors augmented cell migration and metastasis through induction of PKCs leading to identification of low toxicity modalities for combination cancer therapy. Clin Cancer Res. 2012;18(17): 4691-701.

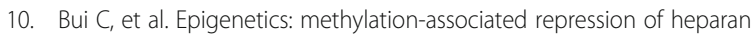
sulfate 3-O-sulfotransferase gene expression contributes to the invasive phenotype of H-EMC-SS chondrosarcoma cells. FASEB J. 2010;24(2):436-50. 
11. Horvat $\mathrm{T}$, et al. Epigenetic modulation of the HeLa cell membrane Nglycome. Biochim Biophys Acta. 2012;1820(9):1412-9.

12. Klasic M, et al. DNA hypomethylation upregulates expression of the MGAT3 gene in HepG2 cells and leads to changes in N-glycosylation of secreted glycoproteins. Sci Rep. 2016;6:24363.

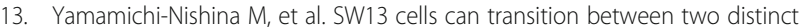
subtypes by switching expression of BRG1 andBrm genes at the posttranscriptional level. J Biol Chem. 2003;278(9):7422-30.

14. Davis MR, et al. Epigenetically maintained SW13+ and SW13- subtypes have different oncogenic potential and convert with HDAC1 inhibition. BMC Cancer. 2016;16(1):1-13.

15. O'Connell MP, et al. Heparan sulfate proteoglycan modulation of Wnt5A signal transduction in metastatic melanoma cells. J Biol Chem. 2009; 284(42):28704-12

16. Yamamichi $\mathrm{N}$, et al. The Brm gene suppressed at the post-transcriptional level in various human cell lines is inducible by transient HDAC inhibitor treatment, which exhibits antioncogenic potential. Oncogene. 2005;24(35):5471-81.

17. Neesse A, et al. Pancreatic stellate cells potentiate proinvasive effects of SERPINE2 expression in pancreatic cancer xenograft tumors. Pancreatology. 2007;7(4):380-5.

18. Buchholz $M$, et al. SERPINE2 (protease nexin I) promotes extracellular matrix production and local invasion of pancreatic tumors in vivo. Cancer Res. 2003;63(16):4945-51.

19. Yip CW, et al. Granulin-epithelin precursor interacts with heparan sulfate on liver cancer cells. Carcinogenesis. 2014;35(11):2485-94.

20. Habibi S, et al. A study of lipid- and protein- bound sialic acids for the diagnosis of bladder cancer and their relationships with the severity of malignancy. Rep Biochem Mol Biol. 2014;2(2):70-5.

21. Zhao R, et al. Lectin array and glycogene expression analyses of ovarian cancer cell line A2780 and its cisplatin-resistant derivate cell line A2780-cp. Clin Proteomics. 2017;14:20

22. Wu J, et al. Characterization of site-specific glycosylation of secreted proteins associated with multi-drug resistance of gastric cancer. Oncotarget. 2016;7(18):25315-27.

23. Cerquetti $L$, et al. C-MYC modulation induces responsiveness to paclitaxel in adrenocortical cancer cell lines. Int J Oncol. 2015:46(5):2231-40.

24. Strobeck MW, et al. Compensation of BRG-1 function by Brm: INSIGHT INTO THE ROLE OF THE CORE SWI.SNF SUBUNITS IN RETINOBLASTOMA TUMOR SUPPRESSOR SIGNALING. J Biol Chem. 2002;277(7):4782-9.

25. Gagliano T, et al. Mitotane enhances doxorubicin cytotoxic activity by inhibiting P-gp in human adrenocortical carcinoma cells. Endocrine. 2014;47(3):943-51.

26. Hauselmann I, Borsig L. Altered tumor-cell glycosylation promotes metastasis. Front Oncol. 2014:4:28.

27. Zhu Y, et al. Suppression of a sialyltransferase by antisense DNA reduces invasiveness of human colon cancer cells in vitro. Biochim Biophys Acta. 2001; 1536(2-3):148-60

28. Wang TY, et al. Treating Colon Cancer cells with FK228 reveals a link between histone lysine acetylation and extensive changes in the cellular proteome. Sci Rep. 2015;5:18443.

29. Lundby A, et al. Proteomic Analysis of Lysine Acetylation Sites in Rat Tissues Reveals Organ Specificity and Subcellular Patterns. Cell Rep. 2(2):419-31.

30. Choudhary $C$, et al. The growing landscape of lysine acetylation links metabolism and cell signalling. Nat Rev Mol Cell Biol. 2014;15(8):536-50.

31. Choudhary C, et al. Lysine acetylation targets protein complexes and co-regulates major cellular functions. Science. 2009:325(5942):834-40.

32. Das C, Kundu TK. Transcriptional regulation by the acetylation of nonhistone proteins in humans -- a new target for therapeutics. IUBMB Life 2005;57(3):137-49.

33. Spange $S$, et al. Acetylation of non-histone proteins modulates cellular signalling at multiple levels. Int J Biochem Cell Biol. 2009;41(1):185-98.

34. Dall'Olio F, Trinchera M. Epigenetic Bases of Aberrant Glycosylation in Cancer. Int J Mol Sci. 2017:18(5):998

35. Neelamegham S, Mahal LK. Multi-level regulation of cellular glycosylation: from genes to transcript to enzyme to structure. Curr Opin Struct Biol. 2016; 40:145-52.

36. Rondanino C, et al. Sugar-dependent nuclear import of glycosylated proteins in living cells. Glycobiology. 2003;13(7):509-19.

37. Reeves R, Chang D, Chung SC. Carbohydrate modifications of the high mobility group proteins. Proc Natl Acad Sci U S A. 1981;78(11):6704-8.

38. Dall'Olio F, et al. Sialosignaling: sialyltransferases as engines of self-fueling loops in cancer progression. Biochim Biophys Acta. 2014;1840(9):2752-64.
39. Tan Z, et al. Altered N-glycan expression profile in epithelial-to-mesenchymal transition of NMuMG cells revealed by an integrated strategy using mass spectrometry and Glycogene and lectin microarray analysis. J Proteome Res. 2014;13(6):2783-95.

40. Jordinson $\mathrm{M}$, et al. Vicia faba agglutinin, the lectin present in broad beans, stimulates differentiation of undifferentiated colon cancer cells. Gut. 1999: 44(5):709-14.

41. Li X, et al. Targeting tumor cells by natural anti-carbohydrate antibodies using Rhamnose-functionalized liposomes. ACS Chem Biol. 2016;11(5):1205-9.

42. Karmakar P, et al. Synthesis of a liposomal MUC1 Glycopeptide-based immunotherapeutic and evaluation of the effect of I-Rhamnose targeting on cellular immune responses. Bioconjug Chem. 2016;27(1):110-20.

43. Sheridan RT, et al. Rhamnose glycoconjugates for the recruitment of endogenous anti-carbohydrate antibodies to tumor cells. Chembiochem. 2014;15(10):1393-8.

44. Ramalingam SS, et al. Carboplatin and paclitaxel in combination with either vorinostat or placebo for first-line therapy of advanced non-small-cell lung cancer. J Clin Oncol. 2010;28(1):56-62.

45. Huang $P$, et al. Selective HDAC inhibition by ACY-241 enhances the activity of paclitaxel in solid tumor models. Oncotarget. 2017:8(2):2694-707.

46. Kumar A, et al. The Lewis X-related alpha1,3-fucosyltransferase, Fut10, is required for the maintenance of stem cell populations. J Biol Chem. 2013; 288(40):28859-68

47. Blanas A, et al. Fucosylated antigens in Cancer: an Alliance toward tumor progression, metastasis, and resistance to chemotherapy. Front Oncol. 2018;8:39.

48. Zodro E, et al. FUT11 as a potential biomarker of clear cell renal cell carcinoma progression based on meta-analysis of gene expression data. Tumour Biol. 2014;35(3):2607-17.

49. Mollicone R, et al. Activity, splice variants, conserved peptide motifs, and phylogeny of two new alpha1,3-fucosyltransferase families (FUT10 and FUT11). J Biol Chem. 2009:284(7):4723-38.

50. Uhlen $\mathrm{M}$, et al. A pathology atlas of the human cancer transcriptome. Science. 2017:357(6352):eaan2507.

51. Pakkiriswami S, et al. Glycosylated Notch and Cancer. Front Oncol. 2016;6:37.

52. Milde-Langosch K, et al. Prognostic relevance of glycosylation-associated genes in breast cancer. Breast Cancer Res Treat. 2014;145(2):295-305.

53. Takeuchi $\mathrm{H}$, et al. O-glycosylation modulates the stability of epidermal growth factor-like repeats and thereby regulates Notch trafficking. J Biol Chem. 2017; 292(38):15964-73.

54. Chung $W-C$, et al. Lunatic fringe and $p 53$ cooperatively suppress mesenchymal stem-like breast Cancer. Neoplasia. 2017:19(11):885-95.

55. Zhou D. Why are glycoproteins modified by poly-N-acetyllactosamine glyco-conjugates? Curr Protein Pept Sci. 2003;4(1):1-9.

56. Potapenko IO, et al. Glycan gene expression signatures in normal and malignant breast tissue; possible role in diagnosis and progression. Mo Oncol. 2010:4(2):98-118

57. Song K-H, et al. GALNT14 promotes lung-specific breast cancer metastasis by modulating self-renewal and interaction with the lung microenvironment. Nat Commun. 2016;7:13796.

58. Huanna T, et al. GALNT14 mediates tumor invasion and migration in breast cancer cell MCF-7. Mol Carcinog. 2015;54(10):1159-71.

59. Peng R-Q, et al. MicroRNA-214 suppresses growth and invasiveness of cervical Cancer cells by targeting UDP-N-acetyl-a-d-galactosamine:polypeptide NAcetylgalactosaminyltransferase 7. J Biol Chem. 2012;287(17):14301-9.

60. Wu H, et al. MicroRNA-30e functions as a tumor suppressor in cervical carcinoma cells through targeting GALNT7. Transl Oncol. 2017;10(6):876-85.

61. Beum PV, et al. Expression of core 2 beta-1,6-Nacetylglucosaminyltransferase in a human pancreatic cancer cell line results in altered expression of MUC1 tumor-associated epitopes. J Biol Chem. 1999;274(35):24641-8

62. Wang $L$, et al. An a/G polymorphism of core 2 branching enzyme gene is associated with prostate cancer. Biochem Biophys Res Commun. 2005; 331(4):958-63.

63. Fernández-Vega I, et al. Heparan sulfate proteoglycans undergo differential expression alterations in right sided colorectal cancer, depending on their metastatic character. BMC Cancer. 2015;15:742.

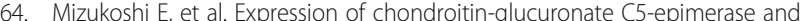
cellular immune responses in patients with hepatocellular carcinoma. Liver Int. 2012:32(10):1516-26.

65. Belyavskaya VA, et al. GLCE rs3865014 (Val597lle) polymorphism is associated with breast cancer susceptibility and triple-negative breast cancer in Siberian population. Gene. 2017;628:224-9. 
66. Fernandez-Vega I, et al. Specific genes involved in synthesis and editing of heparan sulfate proteoglycans show altered expression patterns in breast cancer. BMC Cancer. 2013;13:24.

67. Dai Y, et al. HSulf-1 and HSulf-2 are potent inhibitors of myeloma tumor growth in vivo. J Biol Chem. 2005;280(48):40066-73.

68. Tessema M, et al. SULF2 methylation is prognostic for lung cancer survival and increases sensitivity to topoisomerase-l inhibitors via induction of ISG15. Oncogene. 2012;31(37):4107-16.

69. Honke $\mathrm{K}$, et al. Molecular cloning and expression of CDNA encoding human 3'-phosphoadenylylsulfate:galactosylceramide 3'-sulfotransferase. J Biol Chem. 1997;272(8):4864-8.

70. Liu YY, Hill RA, Li YT. Ceramide glycosylation catalyzed by glucosylceramide synthase and cancer drug resistance. Adv Cancer Res. 2013;117:59-89.

71. Zhao X, et al. Examination of copy number variations of CHST9 in multiple types of hematologic malignancies. Cancer Genet Cytogenet. 2010;203(2):176-9.

72. Ema A, et al. Identification of EGFR expression status association with metastatic lymph node density (ND) by expression microarray analysis of advanced gastric cancer. Cancer Med. 2015;4(1):90-100.

73. Yuan J, et al. CHST9 rs1436904 genetic variant contributes to prognosis of triple-negative breast cancer. Sci Rep. 2017;7(1):11802.

Ready to submit your research? Choose BMC and benefit from:

- fast, convenient online submission

- thorough peer review by experienced researchers in your field

- rapid publication on acceptance

- support for research data, including large and complex data types

- gold Open Access which fosters wider collaboration and increased citations

- maximum visibility for your research: over $100 \mathrm{M}$ website views per year

At $\mathrm{BMC}$, research is always in progress.

Learn more biomedcentral.com/submissions 